\title{
Operational Risk Management in the Process of Assured Quality in Manufacturing Wire Annealed
}

Claudine Guimarães Leite Cardoso ${ }^{1}$, Universidade Federal Fluminense

Vicente Sacramento Junior ${ }^{2}$, Universidade Federal Fluminense

Ualison Rébula de Oliveira ${ }^{3}$, Universidade Federal Fluminense

\section{RESUMO}

Em indústrias siderúrgicas são observadas uma série de riscos em processos provenientes de falhas no controle de parâmetros que afetam diretamente a qualidade dos produtos fornecidos aos clientes. O objetivo deste artigo é identificar as potenciais anomalias durante a execução das atividades na produção de arame. A formulação do plano de tratamento foi realizada através da integração de várias ferramentas no estudo de caso de uma grande usina produtora de aços longos, aplicando o mapeamento de processo, HAZOP e LOPA aliado a análise crítica de especialistas. A aplicação da metodologia permitiu o mapeamento de falhas potenciais e sistematizou a identificação de suas causas agregando conhecimento aos padrões operacionais, permitindo uma abordagem objetiva na detecção e ação assertiva para correção do problema, restringindo que a anomalia em questão interfira na aplicação do produto pelo cliente.

Palavras-chave: Gestão de Riscos. Análise de Risco. HAZOP. LOPA. Arame Recozido.
Editor Responsável: Prof. Dr. Hermes Moretti Ribeiro da Silva

\section{ABSTRACT}

In ironworks industries, a number of risks in processes are observed, due to flaws in the control parameters directly affecting the quality of products supplied to customers. The purpose of this article is to identify potential anomalies during the execution of activities in the production of wire. The formulation of the treatment plan is achieved through the integration of various tools in this case study of a large plant producing long products, applying the mapping process, HAZOP and LOPA combined with critical analysis of experts. The methodology allowed for the identification of potential failures of mapping and was systematized to identify their causes, adding knowledge to operational standards, allowing for an objective approach in the detection of problems and assertive action to fix them by restricting the interference of the anomaly in question with the application of the product by the customer.

Key words: Risk Management. Risk Analysis. HAZOP. LOPA. Annealed Wire.

1. clo.gl@oi.com.br; 2. vicentese@gmail.com; 3. Rua Desembargador Ellis Hermydio Figueira, 783, Aterrado, Volta Redonda, Rio de Janeiro, Brasil, cep 27213-145, ualison.oliveira@gmail.com

CARDOSO, C. G. L.; SACRAMENTO JUNIOR, V.; OLIVEIRA, U. R. Gerenciamento de riscos operacionais no processo de qualidade assegurada na fabricação de arame recozido. GEPROS. Gestão da Produção, Operações e Sistemas, v. 14, n. 4, p. 134 $-155,2019$.

DOI: $10.15675 /$ gepros.v14i4.2307 
Gerenciamento de riscos operacionais no processo de qualidade assegurada na fabricação de arame recozido

\section{INTRODUÇÃO}

O aspecto de controle operacional vem sendo associado à gestão de riscos dentro das organizações, tornando-se cada vez mais importante e admitindo um conceito de maturidade através da adoção em uma visão de processos (MCCORMACK et al., 2009). Desafios nos empreendimentos, tais como concorrências internacionais, aumento da pressão de custos e o ritmo com as exigências do mercado, obrigam as empresas a melhorar os seus processos em segurança, qualidade e custo competitivo dos produtos, proporcionando o desenvolvimento de estratégias corporativas que permitem as empresas concentrarem-se na geração de valor e processos de negócios (NEUBAUER, 2009).

As mudanças no contexto externo e interno das organizações exigem alterações nos critérios de risco estabelecidos, requerendo uma revisão dos tratamentos dos riscos e a priorização periódica estabelecida na rotina das atividades organizacionais (RAZ; MICHAEL, 2001).

Desta forma, a orientação por processos estabelece medições para identificação e compreensão das oportunidades de melhoria, utilizando as combinações de ferramentas e desenvolvendo uma arquitetura na gestão e aplicação do mapeamento dos processos (HELLSTROM; ERIKSSON, 2008). Conforme Balzarova et al. (2004), a implementação de um sistema de gestão baseado em processos é fundamental na melhoria contínua, podendo ser medido através da qualidade do produto e da satisfação do cliente.

A norma ABNT NBR ISO 9001 (2015) explicita que as organizações, independentes do setor em que atuam, devem identificar e gerir os processos que compõem seu sistema de gestão da qualidade, descrevendo oito princípios, dos quais destacam-se: organizações dependem de seus clientes e, portanto, devem entender suas necessidades atuais e futuras, se esforçando para exceder as suas expectativas; um resultado desejado é alcançado mais eficientemente quando os recursos e atividades relacionadas são gerenciados como um processo; abordagem baseada em fatos para a tomada de decisões eficazes são embasadas na análise de dados e informações (PHENGET et al, 2003).

Em sua última revisão, a ISO 9001 abrange a aplicação da mentalidade de risco descrevendo a necessidade do enfoque de ações para abordá-los, assim como associar as oportunidades ao contexto e objetivos organizacionais, determinando os fatores que poderiam 
Gerenciamento de riscos operacionais no processo de qualidade assegurada na fabricação de arame recozido

causar desvios nos seus processos e no seu sistema de gestão da qualidade em relação aos resultados planejados, além de colocar em prática controles preventivos para minimizar efeitos negativos e maximizar o aproveitamento das oportunidades. $\mathrm{O}$ gerenciamento de riscos auxilia a tomada de decisão, levando em consideração as incertezas e a possibilidade de seus efeitos sobre as metas traçadas pela organização.

$\mathrm{Na}$ empresa alvo do presente estudo, a ocorrência da aderência entre as espiras dos rolos de arame após o tratamento térmico de recozimento interfere negativamente na performance do "desbobinamento" no cliente. Os impactos são observados através de indicadores de eficiência e rendimento metálico durante a aplicação do produto, tais como a redução de velocidade de processamento e o excesso de geração de sucata devido às ocorrências de embolo nos rolos de arame recozido.

Assim, considerando os efeitos de falha sobre a propriedade mecânica do arame, a presente pesquisa possui como objetivo geral identificar as potenciais anomalias durante a execução das atividades na produção de arame. $\mathrm{O}$ atingimento de tal objetivo permitirá a organização aumentar a velocidade no diagnóstico das causas com sua consequente tomada de ação para mitigação das ocorrências. Pretende-se atingir tal objetivo por meio do uso integrado de ferramentas de gerenciamento de riscos preconizadas pela norma ISO 31010.

A relevância da pesquisa se encontra no estabelecimento e manutenção de procedimentos de verificação para tomada de medidas preventivas que, segundo Phenget et al. (2003), contribui para um comportamento mais cuidadoso e planejado das atividades de trabalho, planejamento de produção mais confiável, produtos livres de defeitos e um sistema de gestão otimizado com o envolvimento mais abrangente das partes interessadas.

Além dessa introdução, a presente pesquisa estruturou-se por meio das seguintes seções: i) uma revisão da literatura, com foco conceitual nas ferramentas da ISO 31010; sobretudo naquelas que são utilizadas no estudo de caso (HAZOP e LOPA); ii) resultados da pesquisa empírica, com enfoque no controle de parâmetros da qualidade no processo de recozimento de arames (mais precisamente no controle da propriedade mecânica do material); iii) análise e discussão dos resultados; iv) conclusões das implicações práticas da pesquisa.

\section{REFERENCIAL TEÓRICO}

A competitividade entre as organizações vem incentivando o aumento da performance na cadeia de suprimentos, onde a gestão de risco tornou-se uma iniciativa vantajosa na GEPROS. Gestão da Produção, Operações e Sistemas, v. 14, n 4, p. 134 - 155, 2019. 
Gerenciamento de riscos operacionais no processo de qualidade assegurada na fabricação de arame recozido

redução da vulnerabilidade, propondo controle de fatores que causariam efeitos negativos sobre a normalidade dos processos (RANGEL et al., 2015). Nesse contexto, essa seção abordará os seguintes tópicos: Gerenciamento de Riscos, Classificação dos Riscos e Ferramentas para o Gerenciamento de Riscos, conforme segue.

\subsection{Gerenciamento de riscos}

A norma ABNT NBR ISO/IEC 31000 (2009) integra o processo de gestão de risco ao planejamento estratégico, a análise dos resultados, as políticas e cultura da organização, descrevendo sistematicamente o processo detalhado para o gerenciamento de risco nas organizações, através do processo lógico de identificação, análise, avaliação e tratamento de risco. Esta norma abrange os controles dos riscos e implementação de melhoria contínua para que as organizações sejam capazes de reagir à mudanças, além de manter o relacionamento entre as partes interessadas.

A análise e avaliação dos dados devem manter-se de forma confiável, fornecendo base para que de maneira coerente atinja a tomada de decisão da governança de forma eficaz e eficiente, visando: atingir os objetivos da organização; garantir o desempenho em saúde, segurança e meio ambiente; reduzir perdas; facilitar a aprendizagem operacional; encorajar a gestão proativa; facilitar a identificação de oportunidades e ameaças; atender as normas de requisitos legais pertinentes; fornecer base transparente para tomada de ação e planejamento; e alocar recursos de maneira correta (ABNT NBR ISO/IEC 31000, 2009).

Desta forma, o nível de desempenho dos processos será alcançado a partir de um entendimento abrangente de seus riscos, enfatizando a melhoria contínua no estabelecimento de metas anuais seguida de uma revisão de processos e o estabelecimento de objetivos de desempenho revisados para o período. Complementando o raciocínio, será necessário que os "donos" dos processos sejam adequadamente qualificados, se responsabilizando pelas atividades de alocação de recursos adequados para: i) verificar e melhorar controles; ii) monitorar riscos, e; iii) comunicar-se eficazmente com as partes interessadas internas e externas sobre os riscos e sua gestão (ABNT NBR ISO/IEC 31000, 2009).

É importante verificar que a avaliação de riscos envolve a comparação entre o nível de risco encontrado durante o processo de análise com os critérios de risco estabelecidos no contexto, sendo desta forma identificada a necessidade do tratamento do risco; ou a necessidade de uma análise mais aprofundada; ou ainda, a decisão de não tratar o risco de GEPROS. Gestão da Produção, Operações e Sistemas, v. 14, n 4, p. 134 - 155, 2019 
Gerenciamento de riscos operacionais no processo de qualidade assegurada na fabricação de arame recozido

nenhuma outra forma que seja manter os controles existentes. O que se espera é o equilíbrio entre os custos e os esforços de implementação das ações, considerando a percepções das partes interessadas (ABNT NBR ISO/IEC 31000, 2009).

É conveniente que o monitoramento e análise crítica sejam planejados como parte do processo de maneira periódica ou em resposta a um fato específico analisando os eventos, mudanças, tendências, sucessos e fracassos, a fim de se aprender com eles. Desta forma a rastreabilidade e registros se tornam de grande valor, fornecendo e fundamentando as ferramentas aplicadas no processo (ABNT NBR ISO/IEC 31000, 2009).

\subsection{Riscos e tipos de riscos}

A classificação de riscos dentro das cadeias de suprimentos é uma ação que nem sempre apresenta consenso ou padronização entre os pesquisadores do tema. Com isso, Rangel et al. (2015) estratificaram dentro do sistema organizacional os principais tipos de risco. Inicialmente, esses autores descreveram as principais exposições de uma cadeia de suprimentos, conforme segue:

1. Falta de planejamento estratégico e diferença de culturas mantendo a ausência de sistemática para foco nas atividades de produção ou incapacidade de cumprir a legislação vigente.

2. Falha no sistema de tecnologia de informação ou automação tendo como consequência a demora na coleta e interpretação dos dados gerados no processo.

3. Falha em acompanhar as mudanças requeridas pelo mercado consumidor ou fortalecimento de parcerias em suprimentos.

4. Fluxo de caixa ineficiente a mudanças no mercado financeiro ou desastres naturais.

5. Gargalos entre processos de produtos internos com havendo demora na resposta a mudanças de demanda ou desconhecimento da possível carteira dos clientes.

Raz e Michel (2001) descrevem que a escolha dos riscos a serem mitigados é dependente da medição de seus critérios e deve-se estender de modo continuado com foco na natureza e os tipos de causas e consequências que podem ocorrer. Ainda consideram que a evolução no tempo e probabilidade de ocorrência avaliam a pertinência do nível do risco se tornar aceitável ou tolerável. Conforme os autores, o processo de avaliação de risco abrange a identificação de suas fontes, áreas de impactos, eventos e mudanças circunstanciais, além de 
Gerenciamento de riscos operacionais no processo de qualidade assegurada na fabricação de arame recozido

suas causas e consequências potenciais na aplicação de gestão de projetos e no gerenciamento de riscos; descrevendo-os com o objetivo de atuar sobre os procedimentos para identificar, analisar, avaliar e abordar os riscos inerentes a qualquer projeto.

Segundo Manuj e Mentzer (2008), o processo de gerenciar e mitigar os riscos foi desenvolvido em 5 etapas, com foco em cadeias de suprimento global.

Figura 1 - As cinco etapas de SCRM.

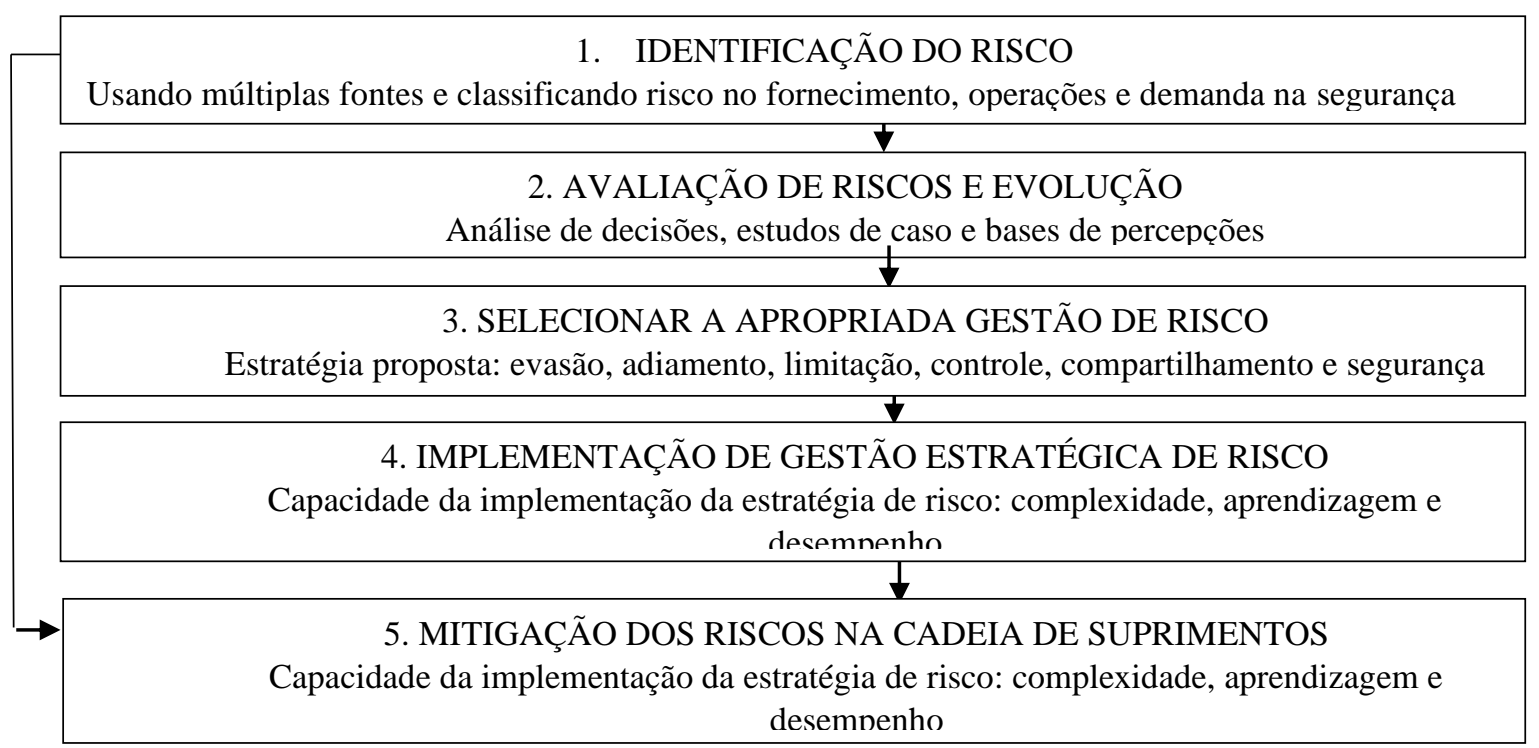

Fonte: Adaptado de Manuj e Mentzer (2008).

\subsection{Aplicação de ferramentas da ABNT NBR ISO/IEC 31010:2009}

Dentre muitas ferramentas que podem ser aplicadas na gestão de riscos, a ABNT (2012) relaciona a aplicabilidade do método de estudo de perigos e operabilidade (HAZOP) aos processos de avaliação de risco, classificando-o como fortemente aplicável na identificação de riscos e análise de suas consequências, além de utilizar a classificação aplicável para a análise na probabilidade de ocorrências, nível de risco e avaliação de risco. A norma ainda enfatiza a relevância da aplicação da técnica identificando os modos de falha, suas causas e consequências por raciocínio indutivo aplicados a sistemas de processo químico, sistemas mecânicos e eletrônicos, procedimentos e sistemas de software e controle de instrumentos críticos.

HAZOP é uma técnica qualitativa utilizada em gestão de riscos cujo objetivo é permitir a correlação entre perigos na operabilidade, variáveis de processo e ação requerida para mitigar ou até eliminar os riscos (KHAN; ABBASI, 1997). Essa ferramenta é baseada no 
Gerenciamento de riscos operacionais no processo de qualidade assegurada na fabricação de arame recozido

questionamento através de palavras guias para projeção de condições de operação de projetos, procedimentos denominados pelo método como "nós" (VAIDHYANATHAN; VENKATASUBRAMANIAN, 1995).

O HAZOP tem como objetivo: identificar os perigos, avaliar os seus fatores de risco e determinar a medida para a promoção do processo e redução de acidentes gerando um ranking classificatório dos riscos em aceitáveis ou inaceitáveis com perdas financeiras ou danos pessoais (SWUSTE et al., 1997). Esta ferramenta é considerada como uma metodologia eficaz para a predição de riscos, contribuindo com elevados níveis de segurança através da prevenção de acidentes e mitigação de problemas operacionais (DIMITRIADIS et al., 1997).

Conforme Dunjó et al. (2010), essa metodologia é regida por um procedimento altamente disciplinado com aplicação sistemática de análise crítica formal do processo avaliando os riscos reais, assim como as intenções e potenciais de risco por mau funcionamento dos equipamentos, referenciando as consequências sobre a instalação da organização.

Srinivasan e Venkatasubramanian (1998) citam que na obtenção de um nível desejado de segurança, a identificação do risco de uma instalação potencialmente perigosa desempenha um papel fundamental, sendo necessário identificar os possíveis incidentes significativos através da aplicação de técnicas de investigação sistemática, incluindo o uso do HAZOP.

Para o desenvolvimento do HAZOP é necessário que existam encontros formais entre membros conhecedores e com experiência no assunto a ser abordado formando uma equipe multidisciplinar durante a análise incluindo uma equipe de especialistas das plantas (processo e instrumentos técnicos, engenheiros de processo e controle, e operadores) liderados por um analista de segurança. A análise é demorada e requer uma grande quantidade de trabalho pois essas pessoas realizam o detalhamento do gerenciamento de riscos e descrevem recomendações de alterações e procedimentos criticando as especificações do projeto (SWUSTE et al., 1997). Mesmo que HAZOP seja uma sistemática estruturada, ainda é dependente da observação humana, bom senso e criatividade (DUNJÓ et al., 2010).

$\mathrm{Na}$ detecção da correlação entre efeito e causa, é possível que seja necessário a aplicação de simulações que comprovem os limites aplicáveis ao processo a ser mensurado no projeto através de simulações, sendo realizadas medições, normalmente quantitativas, em condições diferenciadas considerando as condições de contorno limitantes do processo (LABOVSKÝ et al., 2006). As análises têm intenção investigativa criando uma relação entre GEPROS. Gestão da Produção, Operações e Sistemas, v. 14, nº 4, p. 134 - 155, 2019. 
Gerenciamento de riscos operacionais no processo de qualidade assegurada na fabricação de arame recozido

as alterações deliberadas por dados conectados as variáveis de entrada sobre a projeção da intenção nas respostas das variáveis de saída do projeto (CATINO, 1995).

O próximo passo é a identificação da configurações de fatores a serem otimizados para garantir um processamento ótimo permitindo posteriormente a agilidade nas análise em tempo real melhorando a eficácia nas tomadas de ações em segurança, sustentabilidade e qualidade nas organizações, podendo-se ter como parâmetros chave: as propriedades físicas de um material ou processo; condições físicas como temperatura ou velocidade; intenção especificada de um componente de um sistema ou projeto (por exemplo, transferência de informações); e aspectos operacionais. Para mensurar essas condições, a ABNT (2012) exemplifica as palavras guias utilizada para descrever o comportamento de parâmetros chave através do Quadro 1.

O resultado do HAZOP é a tabulação de modos de falha detectados enquanto no estágio de detalhamento do projeto, podendo contribuir com a agilidade e tomada de ações assertivas pela orientação dos processos e serviços relacionados no sistema (SWUSTE et al., 1997).

Quadro 1 - Exemplo de palavras guia aplicáveis em HAZOP.

\begin{tabular}{|l|l|}
\hline \multicolumn{1}{|c|}{ Termos } & \multicolumn{1}{c|}{ Definições } \\
\hline Nenhum (a) ou não & $\begin{array}{l}\text { Nenhuma parte do resultado pretendido é atingida ou a condição pretendida está } \\
\text { ausente }\end{array}$ \\
\hline Mais (maior) & Aumento quantitativo na saída ou na condição operacional \\
\hline Menos (menor) & Diminuição quantitativa \\
\hline Bem como & Aumento quantitativo (por exemplo, material adicional) \\
\hline Parte de & Diminuição quantitativa (por exemplo, um ou dois componentes em uma mistura) \\
\hline Reverso / oposto & Oposto (por exemplo, retorno de fluxo) \\
\hline Exceto & Algo completamente diferente acontece (por exemplo, fluxo ou material errado) \\
\hline Compatibilidade & Material; ambiente \\
\hline
\end{tabular}

Fonte: ABNT, 2012.

Desta forma, o HAZOP pode ser aplicado em conjunto com outras técnicas como demonstrado na norma ABNT NBR ISO 31010 (2012), considerando uma avaliação da potencial listagem de eventos iniciadores, podem contribuir: a técnica estruturada "E se" (SWIFT) ou uma árvore de falhas (FTA).

Em relação à definiçãa dos nós, pode-se aplicar o mapeamento de processos. Segundo Oliveira et al. (2010), esta técnica é proposta na descrição das relações físicas em um diagrama, gerando assim orientação nas diversas fases do desenvolvimento do projeto, relacionando à compreensão da sequência lógica de procedimentos de um setor, departamento 
Gerenciamento de riscos operacionais no processo de qualidade assegurada na fabricação de arame recozido

ou organização. Ainda conforme o autor, nesta análise são consideradas as relações entre processos e intra-processo, definindo as atividades como: atividades críticas aquelas que implicam na ocorrência da falha, culminando o não cumprimento do propósito do sistema, comprometendo os resultados organizacionais; atividades não críticas as que prejudicarão alguma etapa do processo, não comprometendo a concretização das metas do sistema.

Com a avaliação de probabilidade/consequência é utilizada análise de criticidade estabelecendo prioridades da tabulação HAZOP. Para complementar a matriz pode-se inserir uma visão utilizando o FMEA (análise de modo e efeito de falha) em que a criticidade é uma função que permite uma maior estimativa de um índice de risco (RPN) Risk Priority Number enriquecendo a avaliação do risco a partir da análise da severidade (S), da probabilidade de ocorrência de falha (O) e capacidade de detecção do problema (D) (ABNT, 2012).

Segundo Summers (2003), outra ferramenta que se relaciona bem com o HAZOP é o LOPA - layers of protection analysis -, concebendo uma série de salvaguardas inerentemente seguros, tais como sistemas instrumentados, procedimentos e treinamento; ordenando-os a adição das chamadas camadas de proteção prevendo a modificação do processo ou mudança de procedimentos através da avaliação do custo benefício na seleção do risco associado.

A ABNT (2012) aborda a aplicabilidade da LOPA como uma técnica semiquantitativa de avaliação de riscos cuja finalidade é determinar se as camadas de proteção associadas a um cenário acidental são suficientes para reduzir a sua frequência de ocorrência a um nível considerado tolerável classificando-a como fortemente aplicável na análise das consequências no processo de avaliação de riscos permitindo concentrar recursos nas camadas de proteção mais críticas e identificação de operações com salvaguardas insuficientes.

Conforme Khalil et al. (2012), para evitar a perda de produção ou baixa disponibilidade de produtos ou equipamentos, o LOPA é entendido como um sistema de probabilidade condicional que exige atuação considerando a possibilidade de ocorrência de falha em um determinado período de processamento, mantendo resultados a níveis aceitáveis e prevendo posterior risco adicional ao sistema, identificando cenários falhos e reduzindo a frequência de consequências indesejáveis. 
Gerenciamento de riscos operacionais no processo de qualidade assegurada na fabricação de arame recozido

Figura 2 - Camadas disponíveis de defesa contra um certo cenário perigoso.

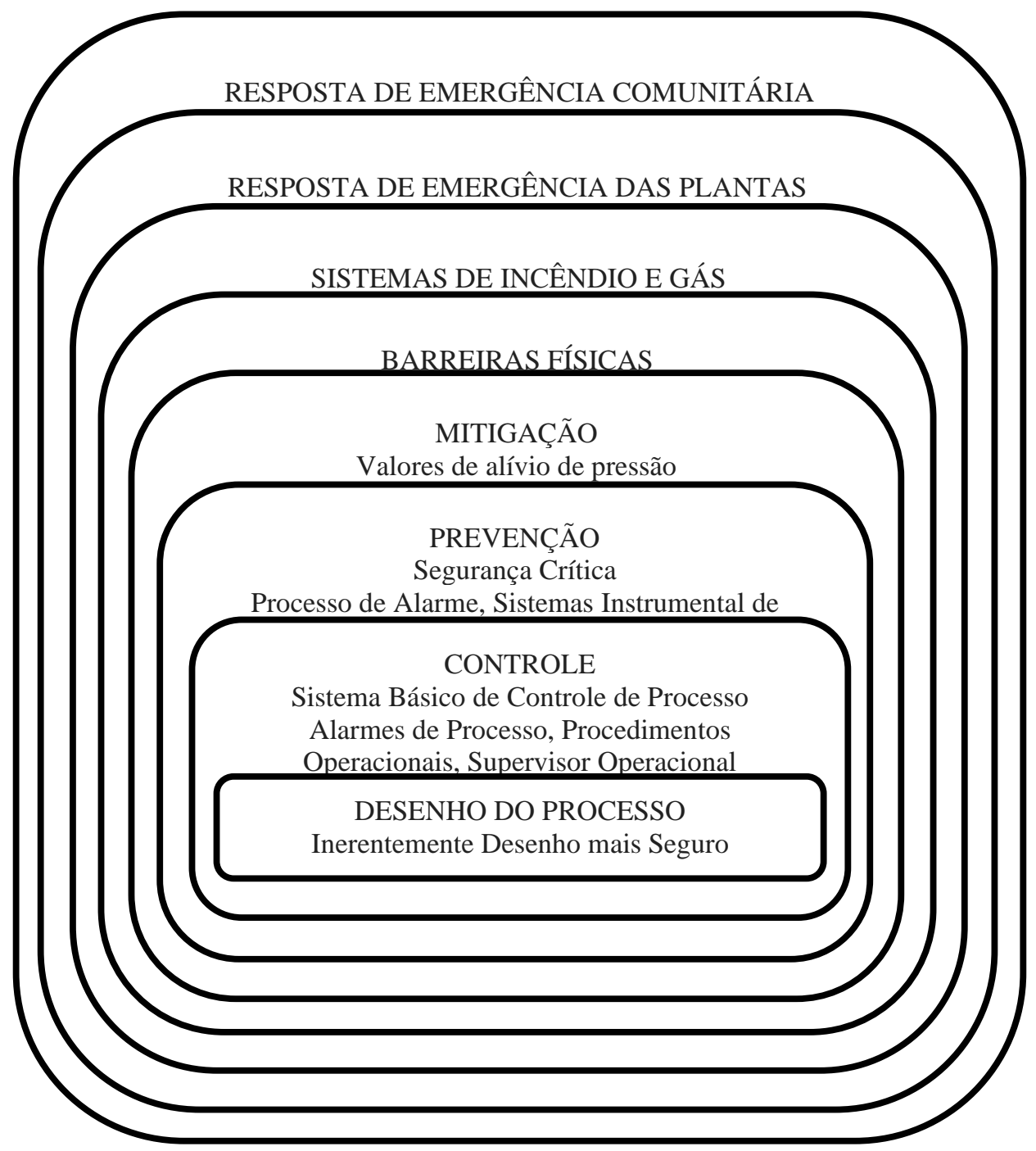

Fonte: Adaptado de Khalil et al., 2012.

\section{PROCEDIMENTOS METODOLÓGICOS}

\subsection{Objeto de estudo}

O trabalho foi desenvolvido considerando o monitoramento e intervenção no forno de recozimento através dos passos de identificação, observação, análise, mensuração e formulação do plano de ação para proposta de uma abordagem sobre a propriedade mecânica necessária para o manuseio do arame recozido na construção civil, aplicado para amarração de estruturas metálicas nas aplicações de pisos, colunas, vigas e lajes nas construções no Brasil. A normalização deste produto é abordada pela ABNT NBR 5589 (2012) restringindo o 
Gerenciamento de riscos operacionais no processo de qualidade assegurada na fabricação de arame recozido

limite de resistência máximo em $56 \mathrm{kgf} / \mathrm{mm}^{2}$ mesmo que o mercado admita valores inferiores a $42 \mathrm{kgf} / \mathrm{mm}^{2}$.

A identificação das causas da anomalia foi realizada através da priorização por especialistas na observação das etapas do mapeamento do processo, considerando a abordagem do problema descrito pelo cliente como aderência das espiras de arame recozido no interior dos rolos.

O levantamento dos modos de falhas foi descrito na análise dos riscos e mensurados dados referentes às propriedades mecânicas do produto em relação aos parâmetros de processo de tempo e temperatura do forno de recozimento.

No plano de ação, as causas foram correlacionadas aos modos de falha, sendo traçados os meios de detecção, salvaguardas e responsáveis pelos controles do processo.

\subsection{Procedimentos de coleta de dados}

Com o auxílio e a opinião dos especialistas, a identificação do processo crítico foi realizada através da determinação do principal nó do mapeamento de processo com a seleção do recozimento como etapa principal para verificação do processo, tendo como objetivo a garantia da propriedade máxima do arame sem haver outros efeitos negativos para a aplicação do cliente como a adesão entre as espiras no rolo.

O estudo de caso considerou a observação da anomalia em área produtiva e o uso de entrevistas realizadas em pequenas reuniões utilizando inicialmente a abordagem do "brainstorming" com seis gestores do ambiente produtivo estudado, considerando as especialidades na área da gestão da qualidade, assim como engenharia de produção, processos e manutenção. Logo em seguida, foi realizado o mapeamento do processo e uma pré-análise com os especialistas para a priorização da etapa crítica, definindo a necessidade de testes e simulações de temperatura e tempo do processo no forno de recozimento, considerando os efeitos de falha sobre a propriedade mecânica do arame.

\subsection{Procedimentos de análise de dados}

Para o desenvolvimento da abordagem de simulação, foi utilizado o software Minitab 14 após o traçado do experimento sequencial sob o formato "design of experiment" (DOE), permitindo a identificação de configurações dos fatores tempo e temperatura que otimizassem a resposta limite de resistência do arame recozido. Desta forma, houve a extrapolação de GEPROS. Gestão da Produção, Operações e Sistemas, v. 14, no 4, p. 134 - 155, 2019. 
Gerenciamento de riscos operacionais no processo de qualidade assegurada na fabricação de arame recozido

valores máximos e mínimos e, na aplicação destes fatores foi possível fornecer um subconjunto para a análise dos dados incluindo réplicas para minimizar o erro do sistema. Posteriormente, na área produtiva foi realizada a verificação de ocorrência de adesão das espiras nos rolos processados validando ou reprovando o subconjunto de fatores utilizados.

A partir deste conjunto de experimentos, foi necessário extrair todas as possíveis variáveis a serem utilizadas para a geração dos desvios HAZOP combinando os resultados dos experimentos com as palavras-guias temperatura e tempo de encharque, estimando os principais efeitos dos fatores a serem aplicados.

Dentre as palavras guias utilizadas, foram abordados os desvios:

- Não (nenhuma) temperatura de encharque;

- Mais (maior) temperatura ou tempo de encharque;

- Menos (menor) temperatura ou tempo de encharque.

Desta forma, o perfil do ciclo térmico esperado no decorrer do processo de recozimento foi traçado podendo ser criticado através da análise de risco integrada com camadas LOPA tendo abordagens na aplicação de respostas condicionadas a programação da automação do sistema ou abordagens dos padrões de processo e operacionais, adequando informações importantes para a qualidade do produto, considerando a triagem das mudanças consideradas normais como resposta a perturbações assumidas. 
Gerenciamento de riscos operacionais no processo de qualidade assegurada na fabricação de arame recozido

Figura 3 - Esquema metodológico da pesquisa demonstrando aplicação das ferramentas ordenadas segundo a sequência lógica e detalhamento.

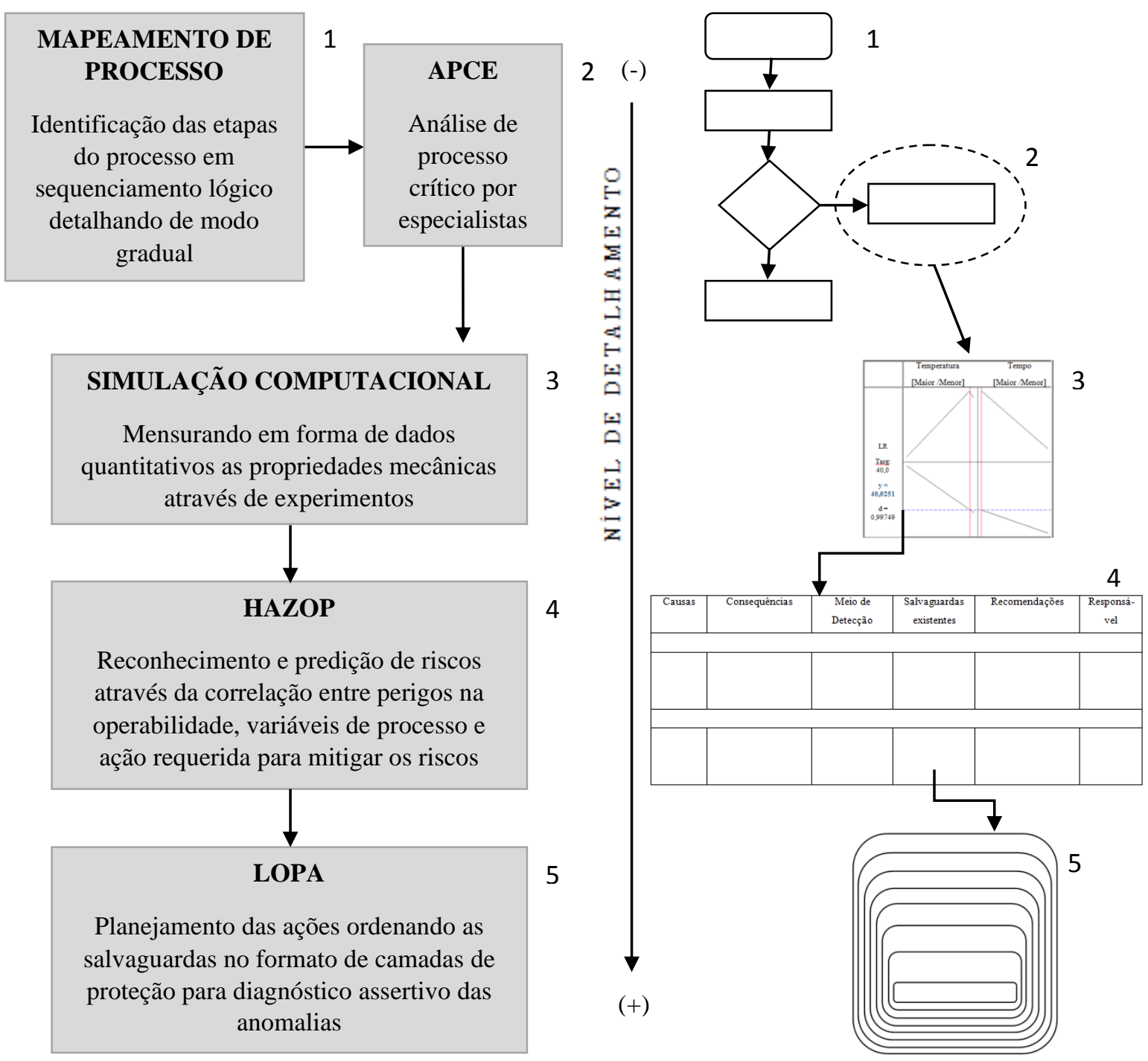

Fonte: Adaptado de Oliveira et al., 2010.

\section{RESULTADOS}

Para identificar as etapas do processo, organizando a sequência em que as tarefas ocorrem, foi descrito os detalhes aplicados a um gráfico esquemático permitindo a visualização em nível macro. Pode-se verificar no processo que ocorre a transformação do fio máquina em arames produzindo uma mudança permanente com o processo de trefilação, sendo realizadas as sub etapas de decapagem e lubrificação para posterior conformação mecânica adequando a geometria do material. Neste momento, ocorre a deformação plástica da seção transversal do arame em severas condições pela aplicação do trabalho a frio tendo GEPROS. Gestão da Produção, Operações e Sistemas, v. 14, nº 4, p. 134 - 155, 2019. 
Gerenciamento de riscos operacionais no processo de qualidade assegurada na fabricação de arame recozido

como consequência a alteração microestrutural, e assim o incremento de propriedades mecânicas e redução da ductilidade como decorrência do encruamento do metal. O arame é bobinado em rolos e destinado ao processo de recozimento no forno, revertendo a condições próximas ao seu estado anterior, sendo objetivada a restauração da ductilidade do metal. O processo de recozimento é compreendido pelo aquecimento, encharque a temperatura constante e resfriamento lento atingindo os três estágios metalúrgicos: recuperação, recristalização e crescimento de grão. Para finalizar as atividades os rolos são embalados em pacotes e destinados a área de estocagem para ser enviados a clientes.

Figura 4 - Diagrama sistemático do processo e determinação de nós na fabricação de arames recozidos.

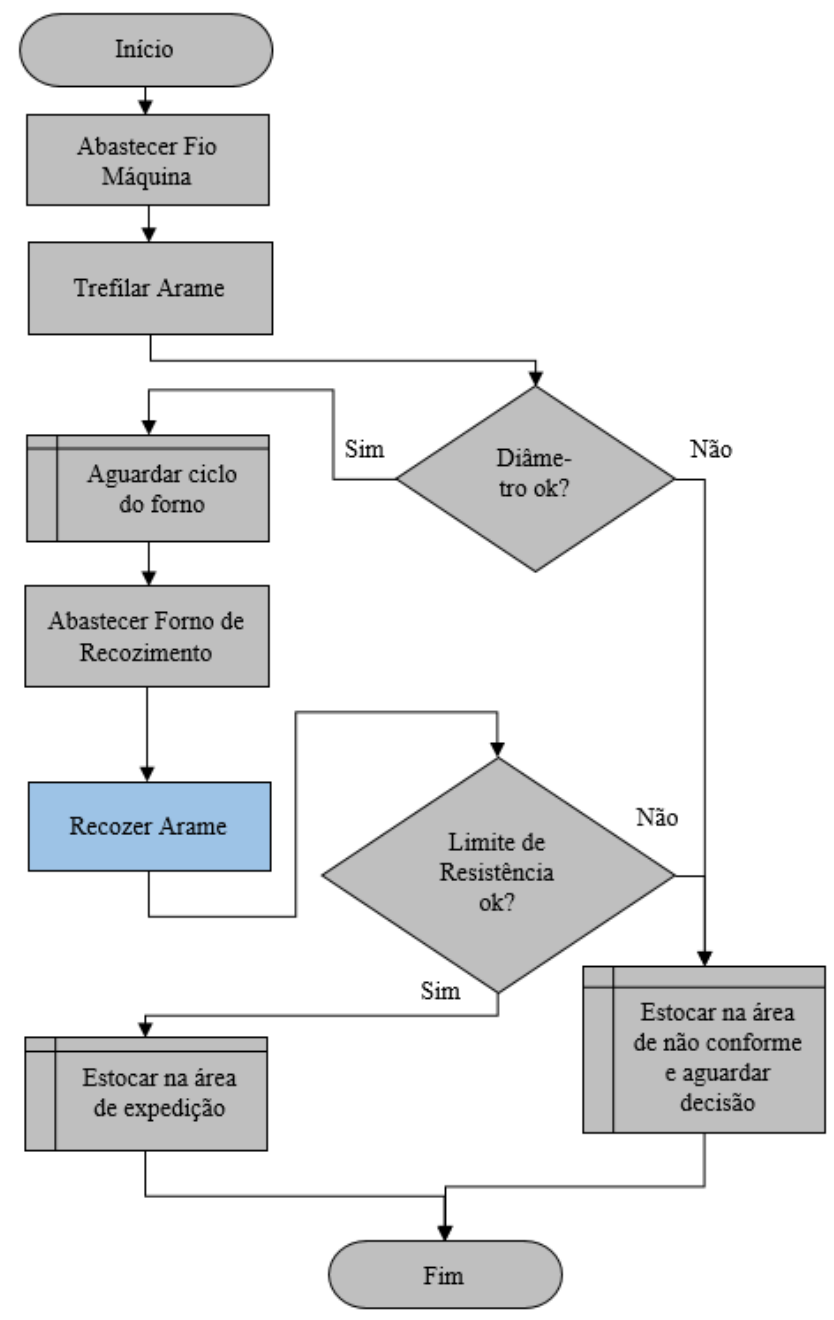

Fonte: Os autores. 
Gerenciamento de riscos operacionais no processo de qualidade assegurada na fabricação de arame recozido

Como contribuições dos especialistas, foi realizado o "brainstorming" sendo identificados os potenciais fatores críticos considerando a falhas no processo que levariam a reprovação do material identificando assim, a prioridade do estudo dos parâmetros do processo de recozimento do arame: tempo e temperatura de encharque.

Foi realizada uma abordagem baseada em modelo do DOE com subconjunto de experimentos derivados da descrição quantitativa e monitoramento da variação de tempo e temperatura de encharque no recozimento. Ainda de forma quantitativa foram realizados ensaios mecânicos para a determinação dos resultados do limite de resistência a cada subconjunto do experimento, porém a última análise foi realizada de forma qualitativa implicando em inspeção visual para determinação da ocorrência de aderência entre as espiras do rolo.

Figura 5 - Avaliação da estabilidade dos resultados dos ensaios mecânicos na determinação do limite de resistência do arame recozido.

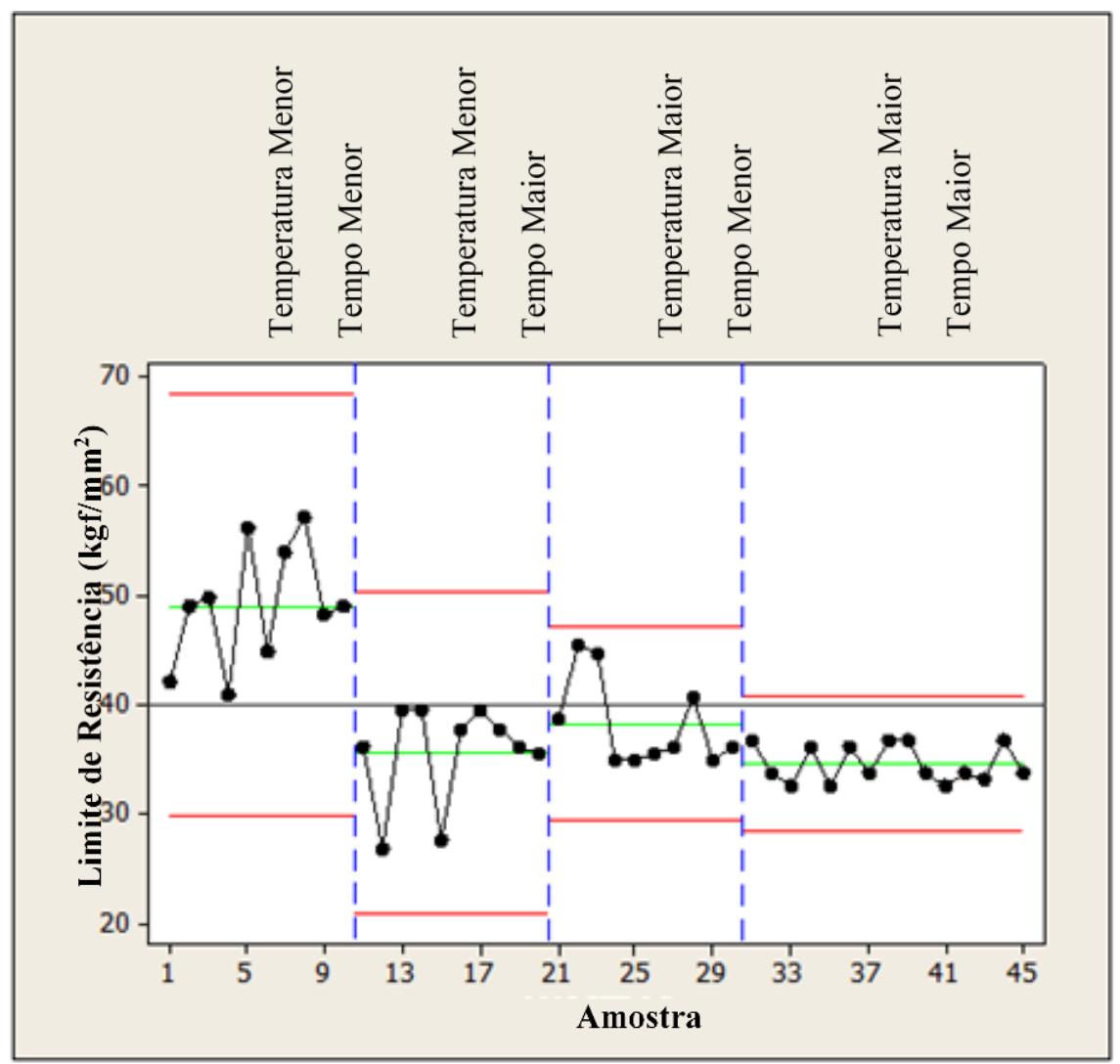

Fonte: Os autores. 
Gerenciamento de riscos operacionais no processo de qualidade assegurada na fabricação de arame recozido

Foi possível traçar a simulação no software Minitab 14 exibindo 95\% dos intervalos de confiança, tendo como resultado médio do limite de resistência do arame (LR) a regressão:

$\mathrm{LR}=130-(0,100 \times$ Temperatura de Encharque $)-(0,149 \times$ Tempo de Encharque $) . A$ Figura 6 aborda os resultados dessa simulação.

Figura 6 - Representação da simulação computacional referente a regressão da relação entre limite de resistência (LR), temperatura de encharque e tempo de encharque.

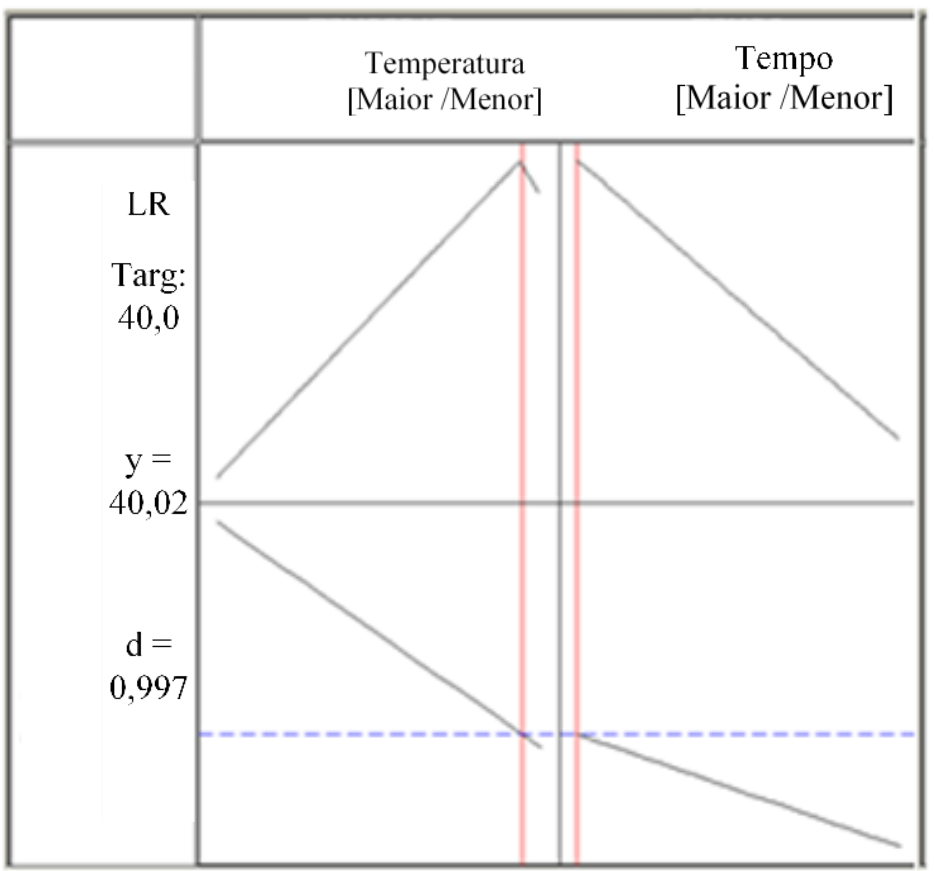

Fonte: Os autores.

Através dos quadros pode-se observar a aplicação de HAZOP para detalhar as consequências no nó recozer arame, assim como as ações detalhadas de atuação das equipes operacionais e de manutenção.

Quadro 2 - Descrição do HAZOP atribuídas as falhas de tempo de encharque.

\begin{tabular}{|c|c|l|l|l|l|}
\hline Causas & Consequências & \multicolumn{1}{|c|}{$\begin{array}{c}\text { Meio de } \\
\text { Detecção }\end{array}$} & $\begin{array}{l}\text { Salvaguardas } \\
\text { existentes }\end{array}$ & Recomendações & Responsável \\
\hline Mais (maior) Tempo & Supervisores \\
\hline $\begin{array}{c}\text { Set point } \\
\text { incorreto } \\
\text { do tempo } \\
\text { de } \\
\text { encharque }\end{array}$ & $\begin{array}{l}\text { Adesão entre } \\
\text { espiras do rolo }\end{array}$ & $\begin{array}{l}\text { Sinais do } \\
\text { supervisório } \\
\text { para inspeção de } \\
\text { controle de } \\
\text { processo }\end{array}$ & $\begin{array}{l}\text { Inspeção } \\
\text { visual durante } \\
\text { embalagem e } \\
\text { estoque }\end{array}$ & $\begin{array}{l}\text { Assegurar } \\
\text { disciplina } \\
\text { operacional }\end{array}$ & \\
\hline \multicolumn{2}{|l|}{ Menos (menor) Tempo } & Sinais do & Ensaio & Assegurar & Supervisores \\
\hline \multicolumn{2}{|l|}{ Set point } & Limite de &
\end{tabular}

GEPROS. Gestão da Produção, Operações e Sistemas, v. 14, n 4, p. 134 - 155, 2019. 


\begin{tabular}{|c|l|l|l|l|l|}
\hline $\begin{array}{c}\text { incorreto } \\
\text { do tempo } \\
\text { de } \\
\text { encharque }\end{array}$ & $\begin{array}{l}\text { resistência } \\
\text { superior a } \\
\text { especificação }\end{array}$ & $\begin{array}{l}\text { supervisório } \\
\text { para inspeção de } \\
\text { controle de } \\
\text { processo }\end{array}$ & $\begin{array}{l}\text { mecânico em } \\
\text { laboratório }\end{array}$ & $\begin{array}{l}\text { disciplina } \\
\text { operacional }\end{array}$ & \\
\hline
\end{tabular}

Fonte: Os autores.

Quadro 3 - Descrição do HAZOP atribuídas as falhas de temperatura de encharque.

\begin{tabular}{|c|c|c|c|c|c|}
\hline Causas & Consequências & $\begin{array}{l}\text { Meio de } \\
\text { Detecção }\end{array}$ & $\begin{array}{c}\text { Salvaguardas } \\
\text { Existentes } \\
\end{array}$ & Recomendações & Responsável \\
\hline \multicolumn{6}{|c|}{ Não (nenhuma) Temperatura } \\
\hline $\begin{array}{l}\text { Forno não } \\
\text { inicia } \\
\text { operação }\end{array}$ & $\begin{array}{l}\text { Limite de } \\
\text { resistência } \\
\text { superior a } \\
\text { especificação }\end{array}$ & $\begin{array}{l}\text { Resposta } \\
\text { negativa da } \\
\text { temperatura no } \\
\text { termopar }\end{array}$ & $\begin{array}{l}\text { Uso de } \\
\text { termopares } \\
\text { calibrados }\end{array}$ & $\begin{array}{l}\text { Garantir } \\
\text { disponibilidade de } \\
\text { termopares através } \\
\text { da rota de inspeção } \\
\text { e manutenção }\end{array}$ & Manutenção \\
\hline \multicolumn{6}{|c|}{ Mais (maior) Temperatura } \\
\hline $\begin{array}{c}\text { Excesso } \\
\text { de chama } \\
\text { no } \\
\text { queimador }\end{array}$ & $\begin{array}{l}\text { Adesão entre } \\
\text { espiras do rolo }\end{array}$ & $\begin{array}{l}\text { Alarme de sobre } \\
\text { temperatura }\end{array}$ & $\begin{array}{l}\text { Limitação da } \\
\text { lógica a }+3 \% \\
\text { da temperatura } \\
\text { de set point }\end{array}$ & $\begin{array}{l}\text { Assegurar } \\
\text { regulagem da } \\
\text { válvula de gás } \\
\text { através da rota de } \\
\text { manutenção }\end{array}$ & Manutenção \\
\hline $\begin{array}{c}\text { Excesso } \\
\text { de chama } \\
\text { no } \\
\text { queimador }\end{array}$ & $\begin{array}{l}\text { Adesão entre } \\
\text { espiras do rolo }\end{array}$ & $\begin{array}{l}\text { Alarme de sobre } \\
\text { temperatura }\end{array}$ & $\begin{array}{l}\text { Limitação da } \\
\text { lógica a }+3 \% \\
\text { da temperatura } \\
\text { de set point }\end{array}$ & $\begin{array}{l}\text { Inspecionar } \\
\text { material na } \\
\text { embalagem e } \\
\text { solicitar verificação } \\
\text { da vazão de gás } \\
\end{array}$ & Operação \\
\hline $\begin{array}{c}\text { Excesso } \\
\text { de chama } \\
\text { no } \\
\text { queimador }\end{array}$ & $\begin{array}{l}\text { Adesão entre } \\
\text { espiras do rolo }\end{array}$ & $\begin{array}{l}\text { Desligamento } \\
\text { automático do } \\
\text { forno }\end{array}$ & $\begin{array}{l}\text { Limitação da } \\
\text { temperatura } \\
\text { máxima do } \\
\text { forno de } \\
\text { recozimento } \\
\end{array}$ & $\begin{array}{l}\text { Inspecionar } \\
\text { material na } \\
\text { embalagem e } \\
\text { solicitar verificação } \\
\text { da vazão de gás }\end{array}$ & Operação \\
\hline $\begin{array}{c}\text { Excesso } \\
\text { de chama } \\
\text { no } \\
\text { queimador }\end{array}$ & $\begin{array}{l}\text { Adesão entre } \\
\text { espiras do rolo }\end{array}$ & $\begin{array}{l}\text { Sinais do } \\
\text { supervisório } \\
\text { para inspeção de } \\
\text { controle de } \\
\text { processo }\end{array}$ & $\begin{array}{l}\text { Limitação da } \\
\text { lógica a }+3 \% \\
\text { da temperatura } \\
\text { de set point }\end{array}$ & $\begin{array}{l}\text { Inspecionar } \\
\text { material na } \\
\text { embalagem e } \\
\text { solicitar verificação } \\
\text { da vazão de gás }\end{array}$ & Inspetores \\
\hline \multicolumn{6}{|c|}{ Menos (menor) Temperatura } \\
\hline $\begin{array}{c}\text { Chama } \\
\text { baixa no } \\
\text { queimador }\end{array}$ & $\begin{array}{l}\text { Limite de } \\
\text { resistência } \\
\text { superior a } \\
\text { especificação }\end{array}$ & $\begin{array}{l}\text { Sinais do } \\
\text { supervisório } \\
\text { para inspeção de } \\
\text { controle de } \\
\text { processo }\end{array}$ & $\begin{array}{l}\text { Limitação da } \\
\text { lógica a } \\
\text { temperatura de } \\
\text { recozimento }\end{array}$ & $\begin{array}{l}\text { Dobrar número de } \\
\text { ensaios mecânicos } \\
\text { verificando } \\
\text { necessidade de } \\
\text { retrabalho no } \\
\text { recozimento }\end{array}$ & Inspetores \\
\hline
\end{tabular}

Fonte: Os autores.

Para complementar o estudo permitindo a visualização completa da instalação do forno, foi discutida e traçada a análise de risco integrada por camadas permitindo o funcionamento otimizado do processo de recozimento aplicada a qualidade assegurada para atendimento dos clientes. 
Gerenciamento de riscos operacionais no processo de qualidade assegurada na fabricação de arame recozido

Figura 7 - Representação da LOPA com as camadas disponíveis aplicada a qualidade assegurada no processo de recozimento.

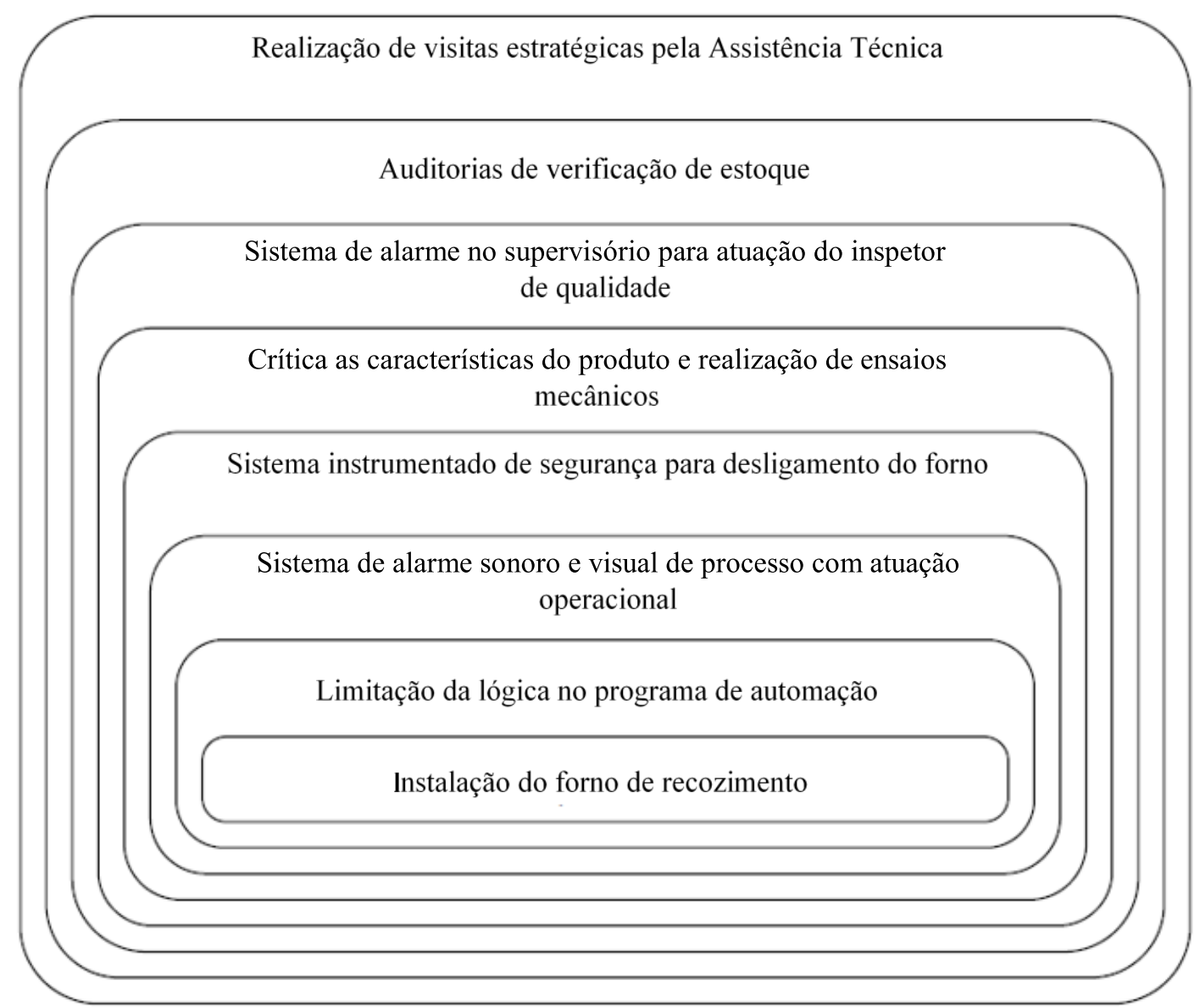

Fonte: Adaptado de Khalil et al., 2012.

\section{DISCUSSÕES}

O mapeamento do processo permitiu a visualização das atividades e previsão das tarefas operacionais de modo a construir o sequenciamento lógico desde a aplicação da matéria prima até a estocagem do arame recozido possibilitando a observação entre a relação dos nós aplicados a cada etapa de produção.

Através da opinião dos especialistas foi possível a economia de tempo e recursos, evitando desvios desnecessários para examinar os processos que não são críticos, já que apenas as falhas de processos críticos que podem comprometer o funcionamento do sistema será completamente mapeada e deverão ser priorizadas orientando a análise de falhas por 
Gerenciamento de riscos operacionais no processo de qualidade assegurada na fabricação de arame recozido

ordem de gravidade e urgência, dando sequência ao levantamento de falhas por meio de suas relações de causa e efeito (OLIVEIRA et. al., 2010).

Neste raciocínio, a aplicabilidade deste método foi validada por diferentes ramos organizacionais em que equipes multidisciplinares atuaram no levantamento e tratamento das falhas de processos de forma a contribuir de maneira mais eficiente e eficaz na solução de problemas. Com isso, a identificação de anomalias foi possível pela projeção de impactos no resultado da qualidade dos arames recozidos através da priorização durante a observação da atividade crítica recozer arame, sendo o alvo da observação e análise na detecção de falhas por comprometer a propriedade mecânica do produto, sendo estas: adesão entre espiras do rolo e limite de resistência superior a especificação.

Para mensurar o comportamento entre o relacionamento da propriedade mecânica do arame recozido e as variações na aplicação dos parâmetros tempo e temperatura do sistema, a aplicação da simulação por "software" permitiu a análise por palavras guia limitando as alterações e a previsão das condições de contorno descritas nos quadros HAZOP como meios de detecção e salvaguardas existentes, podendo citar como principais os sinais do supervisório para inspeção de controle de processo, os alarmes de "sobre temperatura" e as limitações na própria lógica de programação do forno. Conforme Catino (1995), esse tipo de investigação cria a relação entre as variáveis de entrada com a projeção sobre as respostas de saída em projetos.

Swuste et al. (1997), descreve que críticas devem ser feitas ao projeto e recomendações devem ser geradas abordando as atuações necessárias na descrição de procedimentos para manter o processo estável. Desta forma, os quadros de descrição HAZOP demonstram a análise das anomalias considerando além das salvaguardas existentes, as considerações das atuações necessárias e responsabilidades das equipes nos níveis operacionais, inspeção, manutenção e supervisão.

Para uma visão abrangente de todo o sistema da qualidade, a aplicação de LOPA foi descrita no planejamento das ações permitindo ordenar as salvaguardas no formato de camadas de proteção, inserindo as auditorias de verificação de estoque e atuação da equipe de assistência técnica junto aos clientes no mercado. Esta atuação como plano de ação demonstra aderência à ideologia de Summers (2003) que descreve que a adição destas camadas contribui no diagnóstico das anomalias com ações de modificação de processo e mudanças de procedimentos além da avaliação de custo benefício do risco associado. 
Gerenciamento de riscos operacionais no processo de qualidade assegurada na fabricação de arame recozido

\section{CONCLUSÕES}

A gestão de riscos executada no processo de arames recozidos demonstrou sucesso pela resposta positiva do "desbobinamento" dos rolos no cliente, sendo detectado o aumento de velocidade de processamento e redução da geração de sucata.

O acompanhamento dos resultados foi executado no período de um ano e não houveram reclamações de clientes referente a aderência de espiras nos rolos que viessem a prejudicar sua performance na aplicação do produto.

A manutenção das propriedades mecânicas foi levada em consideração, não sendo limitada ao atendimento da norma, mas sim na visão do cliente final, buscando atender condições máximas de limite de resistência de $42 \mathrm{kgf} / \mathrm{mm}^{2}$ requeridas pelo mercado consumidor para não comprometer o "market share" da empresa.

O auxílio na tomada de decisões operacionais durante a produção no forno foi baseado da análise e avaliação de riscos através do planejamento das tarefas e identificação clara da ordem de prioridade das decisões. A integração das quatro técnicas se mostrou relevante, em que mapeamento do processo demonstrou a evolução das etapas do processo norteado pela priorização dos especialistas, identificando os pontos críticos que tiveram as suas causas e meios de detecção tabulados através da HAZOP e posteriormente monitorada através das camadas de proteção da LOPA.

Como trabalho futuro, ainda pode-se complementar a metodologia com uma matriz utilizando o FMEA na determinação de criticidade por uma estimativa do índice de risco RPN - “Risk Priority Number”- enriquecendo esta avaliação de risco.

\section{Referências}

ASSOCIAÇÃO BRASILEIRA DE NORMAS TÉCNICAS. Gestão de riscos - Princípios e diretrizes. ABNT NBR ISO/IEC 31000. p. 24,2009.

ASSOCIAÇÃO BRASILEIRA DE NORMAS TÉCNICAS. Gestão de riscos - Técnicas para o processo de avaliação de riscos. ABNT NBR ISO/IEC 31010. p. 96, 2012.

ASSOCIAÇÃO BRASILEIRA DE NORMAS TÉCNICAS. Arame de aço de baixo teor de carbono - Requisitos. ABNT NBR 5589. p. 4, 2012.

ASSOCIAÇÃO BRASILEIRA DE NORMAS TÉCNICAS. Sistemas de gestão da qualidade - Requisitos. ABNT NBR ISO 9001. p. 32, 2015 
Gerenciamento de riscos operacionais no processo de qualidade assegurada na fabricação de arame recozido

BALZAROVA, M.A.; BAMBER, C.J.; McCAMBRIDGE, S.; SHARP, J.M. Key success factors in implementation of process-based management - a UK housing association experience. Business Process Management Journal, v.10, n.4, p.387-99, 2004.

CATINO, C. A.; UNGAR, L. H. Model-based approach to automated hazard identification of chemical plants. AICHE Journal, v.41, n.1, p. 97-109, 1995.

DIMITRIADIS, V. D.; SHAH, N.; PANTELIDES, C. C. Modeling and safety verification of discrete/continuous processing systems. AICHE Journal, v. 43, n.4, p. 1041-1059, 1997.

DUNJÓ, J.; FTHENAKIS, V.; VÍlCHEZ, J. A.; ARNALDOS, J. Hazard and operability (HAZOP) analysis. A literature reviews. Journal of hazardous materials, v.173, n.1, p. 19$32,2010$.

HELLSTROM, A.; ERIKSSON, H. Are you viewing, mapping or managing your processes? The TQM Journal, v.20, n.2, p.166-74, 2008.

KHALIL, M.; ABDOU, M. A.; MANSOUR, M. S.; FARAG, H. A.; OSSMAN, M. E. A cascaded fuzzy-LOPA risk assessment model applied in natural gas industry. Journal of Loss Prevention in the Process Industries, v.25, n.6, p. 877-882, 2012.

KHAN, F. I.; ABBASI, S. A. TOPHAZOP: a knowledge-based software tool for conducting HAZOP in a rapid, efficient yet inexpensive manner. Journal of loss prevention in the process industries, v. 10, n. 5-6, p.333-343, 1997.

LABOVSKÝ, J.; JELEMENSKÝ, L.; MARKOŠ, J. Safety analysis and risk identification for a tubular reactor using the HAZOP methodology. Chemical Papers, v.60, n.6, p. 454-459, 2006.

MANUJ, I.; MENTZER, J. T. Global supply chain risk management. Journal of business logistics, v. 29, n.1, p. 133-155, 2008.

MARCELINO-SÁDABA， S.; PÉREZ-EZCURDIA, A.; LAZCANO, A. M. E.; VILLANUEVA, P. Project risk management methodology for small firms. International Journal of Project Management, v.32, n. 2, p. 327-340, 2014.

MARHAVILAS, P. K.; KOULOURIOTIS, D.; GEMENI, V. Risk analysis and assessment methodologies in the work sites: On a review, classification and comparative study of the scientific literature of the period 2000-2009. Journal of Loss Prevention in the Process Industries, v. 24, n. 5, p. 477-523, 2011.

McCORMACK, K.; WILLEMS, J.; van den BERGH, J.; DESCHOOLMEESTER, D.; WILLAERT, P.; STEMBERGER, M.I.; SKRINJAR, R.; TRKMAN, P.; LADEIRA, M.B.; de OLIVEIRA, M.P.V.; VUKSIC, V.B.; VLAHOVIC, N. A global investigation of key turning points in business process maturity. Business Process Management Journal, v. 15, n.5, p. 792-815, 2009.

NEUBAUER, T. An empirical study about the status of business process management. Business Process Management Journal, v.15, n. 2, p. 166-83, 2009.

OLIVEIRA, U.R.; PAIVA, E.J.; ALMEIDA, D.A. Metodologia Integrada para Mapeamento de Falhas: Uma Proposta de Utilização conjunta fazer mapeamento de processos com técnicas FTA, FMEA e análise crítica de especialistas. Produção, v.20, n.1, p. 77-91, 2010. 
PHENG, L. S.; PONG, C. Y. Integrating ISO 9001 and OHSAS 18001 for construction. Journal of Construction Engineering and Management, v. 129, n.3, p. 338-347, 2003.

RANGEL, D. A.; de OLIVEIRA, T. K.; LEITE, M. S. A. Supply chain risk classification: discussion and proposal. International Journal of Production Research, v.53, n. 22, p. 6868-6887, 2015.

RAZ, T.; MICHAEL, E. Use and benefits of tools for project risk management. International journal of project management, v.19, n.1, p. 9-17, 2001.

SAMPAIO, P.; SARAIVA, P.; RODRIGUES A. G. ISO 9001 certification research: questions, answers and approaches. International Journal of Quality \& Reliability Management, v.26, n. 1, p.38-58, 2009.

SRINIVASAN, R.; VENKATASUBRAMANIAN, V. Automating HAZOP analysis of batch chemical plants: Part II. Algorithms and application. Computers \& Chemical Engineering, v. 22, n. 9, p. 1357-1370, 1998.

SUMMERS, A. E. Introduction to layers of protection analysis. Journal of Hazardous Materials, v. 104, n.1, p. 163-168, 2003.

SWUSTE, P.; GOOSSENS, L.; BAKKER, F.; SCHROVER, J. Evaluation of accident scenarios in a Dutch steel works using a hazard and operability study. Safety Science, v. 26, n. 1, p. 63-74, 1997.

VAIDHYANATHAN, R.; VENKATASUBRAMANIAN, V. Digraph-based models for automated HAZOP analysis. Reliability Engineering \& System Safety, v.50, n.1, p. 33-49, 1995. 